\title{
Non-polyol low-digestible carbohydrates: food applications and functional benefits
}

\author{
Olive Murphy* \\ Leatherhead Food Research Association, Randalls Rd, Leatherhead, Surrey, KT22 7RY, UK
}

\begin{abstract}
Many LDCs currently on the market are not digested in the upper gastrointestinal tract and become fermented in the large intestine. They possess physiological benefits similar to those of dietary fibre. For some of these materials the fermentation process is highly specialised and leads to the selective stimulation and growth of beneficial gut bacteria, e.g. bifidobacteria. These materials are described as prebiotics, which are defined as nutrients fermented in the large bowel that favour the growth of desirable large bowel microflora. This activity has been demonstrated for inulin and oligofructose. Two other carbohydrates with low digestibility that offer desirable physiological properties are resistant starch (RS) and polydextrose (PD). These 'functional' benefits have led to considerable interest from the food industry leading to the use of these ingredients in the development of new 'healthy' products. This paper describes the use of these materials in the development of 'healthy' products, some of their functional properties, and the benefits they confer on different food systems.
\end{abstract}

Inulin: Oligofructose: Polydextrose: Resistant starch: Functional foods

Since the 1980s the 'healthier' food and drinks market has been transformed from a specialist area into a mainstream market. In Europe developments have been led by the UK where the market was valued at $£ 6.7$ billion in 1997 with dairy products as the largest sector (Table 1) (Comber, 1999). Whereas products marketed as 'low-fat' or 'sugarfree' have proved most popular, there has been a developing consumer interest in functional products that contain added ingredients and provide specific health benefits (Young, 1998; Hilliam, 1998). In terms of the functional foods market, the UK was the largest market in Europe, worth an estimated $£ 703$ million in 1997 (Comber, 1999) (Table 2). This included products perceived by consumers as functional foods even if they did not make specific health claims. A product audit survey carried out by the Leatherhead Food Research Association in the same year looked at the availability of functional foods in different European countries and identified that the most frequent claim used was that relating to 'gut health' and the digestive system (Hilliam et al. 1997) (Table 3).

The popularity of these products reflects nutritional guidelines recommending increased dietary fibre intake since low fibre consumption has been implicated as a risk factor in many diseases (British Nutrition Foundation, 1990). Insoluble fibre ingredients, such as bran, have traditionally been used in products such as breakfast cereals, breads and pasta, but the palatability of these materials has limited the level that can be incorporated into different systems. Soluble fibre ingredients are currently of greater interest in the formulation of 'healthy' foods because they are more palatable. In addition, some can be used in food systems to thicken, add viscosity or gel (Dreher, 1999).

\section{Inulin}

Inulin is a natural food ingredient found in many vegetables and obtained industrially from chicory roots (Van Loo, 1995). It is a polydisperse mixture of molecules all with the same basic chemical structure, which can be symbolised as $\mathrm{GFn}$, where $\mathrm{G}$ is the glucosyl moiety, $\mathrm{F}$ is the fructose moiety and $n$ equals the number of fructose moieties linked by $\beta(2 \rightarrow 1)$ linkages (Fig. 1). The degree of polymerisation (DP) of inulin typically ranges from 3 to 60 . Inulin extracted from chicory roots contains up to $10 \%$ of monoand disaccharides, mainly sucrose and fructose, and an oligosaccharide content $(\mathrm{DP}=10)$ of approximately $30 \%$ (Niness, 1999). These products have a low residual sweetness due to mono-, di- and oligosaccharides.

The production process of inulin includes the extraction of the naturally occurring inulin from chicory roots by diffusion in hot water, followed by refining and spray drying. Inulin from which the lower DP-fraction has been physically removed and with an average DP of 25 is available for high-performance fat replacement (Franck, 1997).

\footnotetext{
* Corresponding author: O. Murphy, fax + 44 (0) 1372 386228, email omurphy@ifra.co.uk
} 
Table 1. UK 'healthier' food and drinks market by sector (Comber, 1999)

\begin{tabular}{lc}
\hline Product class & Sector sales (£m) \\
\hline Dairy products & 2138 \\
Yellow fats & 310 \\
Confectionery & 216 \\
Biscuits and cakes & 90 \\
Salad dressings & 152 \\
Snack foods & 75 \\
Jams and preserves & 13 \\
Other 'healthy' prepared foods & 246 \\
Soft drinks & 2400 \\
Hot beverages & 124 \\
Organic foods & 265 \\
Functional foods & 703 \\
Specialist health foods & 443 \\
Total & $6664^{\star}$
\end{tabular}

* Does not represent total of column owing to the inclusion of some yoghurts, soft drinks, confectionery and spreads in the functional foods sector.

The nutritional properties of inulin are based on three factors.

(1) Upon ingestion, inulin is not broken down by the human digestive system and for the purpose of food labelling it is recommended that it should be given an energy value of $6 \cdot 28 \mathrm{~kJ} / \mathrm{g}$ (Roberfroid, 1999a).

(2) Inulin is fermented by colonic bacteria causing an increase in faecal biomass, production of short-chain fatty acids and decrease in caecocolonic $\mathrm{pH}$ and may therefore be classed as a dietary fibre (Roberfroid, 1993).

(3) Ingestion of inulin results in a significant increase of bifidobacteria in the colon and inhibits the growth of less beneficial bacteria (Roberfroid et al. 1998; Roberfroid, 1999b; Van Loo et al. 1999; Kruse et al. 1999).

Using these ingredients in food formulations allows the nutritional value of the endproduct to be improved by increasing the dietary fibre content, reducing the calorie content and increasing the bifidus-promoting capacities.

The recent interest in these ingredients also results from their interesting technological characteristics. Inulin has a neutral taste, is colourless and has minimal influence on the organoleptic characteristics of a product. Combining inulin with high intensity sweeteners significantly improves the taste of products giving a more sugar-like sweetness. Owing to the high solubility of this ingredient over 'classical fibres' inulin can be used to fortify dairy products

Table 2. 'Healthier' food and drinks sales in major European markets (Comber, 1999)

\begin{tabular}{lc}
\hline Country & Sales (£ billion) \\
\hline UK & $6 \cdot 7$ \\
Germany & 4.5 \\
France & $2 \cdot 8$ \\
Italy & $1 \cdot 1$ \\
Spain & $1 \cdot 0$ \\
Total & $16 \cdot 1$ \\
\hline
\end{tabular}

Table 3. Product pick up: 'health' claim analysis (Hilliam et al. 1997)

\begin{tabular}{lr}
\hline Claim & $\%$ \\
\hline Good for stomach/gut/digestion/intestinal flora & 37 \\
Lowers/controls cholesterol & 26 \\
Improves natural defences/boosts immune system & 23 \\
Improves memory/concentration & 3 \\
Strengthens bones/fights osteoporosis & 3 \\
Moisturises skin & 3 \\
Aids relaxation/sleep & 2 \\
Other claims & 3 \\
\hline
\end{tabular}

such as milk drinks, yoghurt, cheeses and desserts, which have been traditionally difficult to fortify (Niness, 1999).

The functionality of inulin is based on its effect on water solutions at various solid levels. At lower concentrations it causes significant viscosity increase and can be used as a rheology modifier. At a concentration of $40-45 \%$ an inulin gel or crème is formed which is firm but with a fatty creamy feel. This crème offers many advantages. Water is tightly bound in the gel, helping to maximise freeze-thaw stability and to inhibit syneresis. In this form inulin is stable in acidic conditions or at high temperatures owing to lack of available water (Silva, 1996). This has created the opportunity for use in 'reduced fat' mayonnaise and salad dressings. It can be used in fat-free products to give a smooth creamy texture and taste. It allows the manufacturer to replace fat containing $37.6 \mathrm{~kJ} / \mathrm{g}$ with an inulin/water combination which has an energy value of $2.09 \mathrm{~kJ} / \mathrm{g}$ or less, resulting in significant calorie reduction (Wouters, 1998).

Inulin has been successfully applied in fat-reduced table spreads, cheese products, meat products, frozen desserts, fillings, sauces and meat replacers (Franck, 1997). Specific applications include the following.

(1) Table spreads: both fat and water form a continuum with inulin, so that inulin can both replace significant amounts of fat and stabilise the emulsion while providing a short spreadable texture.

(2) Breads: inulin crème can be used to increase water addition in doughs as well as moisture retention.

(3) Chocolate: inulin can be used as a sucrose replacer, especially when combined with fructose or polyols.

(4) Ice cream: inulin functions as an inhibitor of water crystal growth.

(5) Dairy-based mousses: the incorporation of 1-5\% inulin enables the product to retain its structure for a longer time and gives a rich fat-like mouthfeel.

\section{Oligosaccharides}

Oligosaccharides of various types are found in many common foods including fruit, vegetables, milk and honey (Van Loo, 1995; Van Loo et al. 1995). The possible health benefits associated with the consumption of these compounds have led to their increased popularity as food ingredients.

Oligosaccharides are generally defined as glycosides having between three and ten simple sugars linked together (Fig. 1) and often contain low levels of monosaccharides 

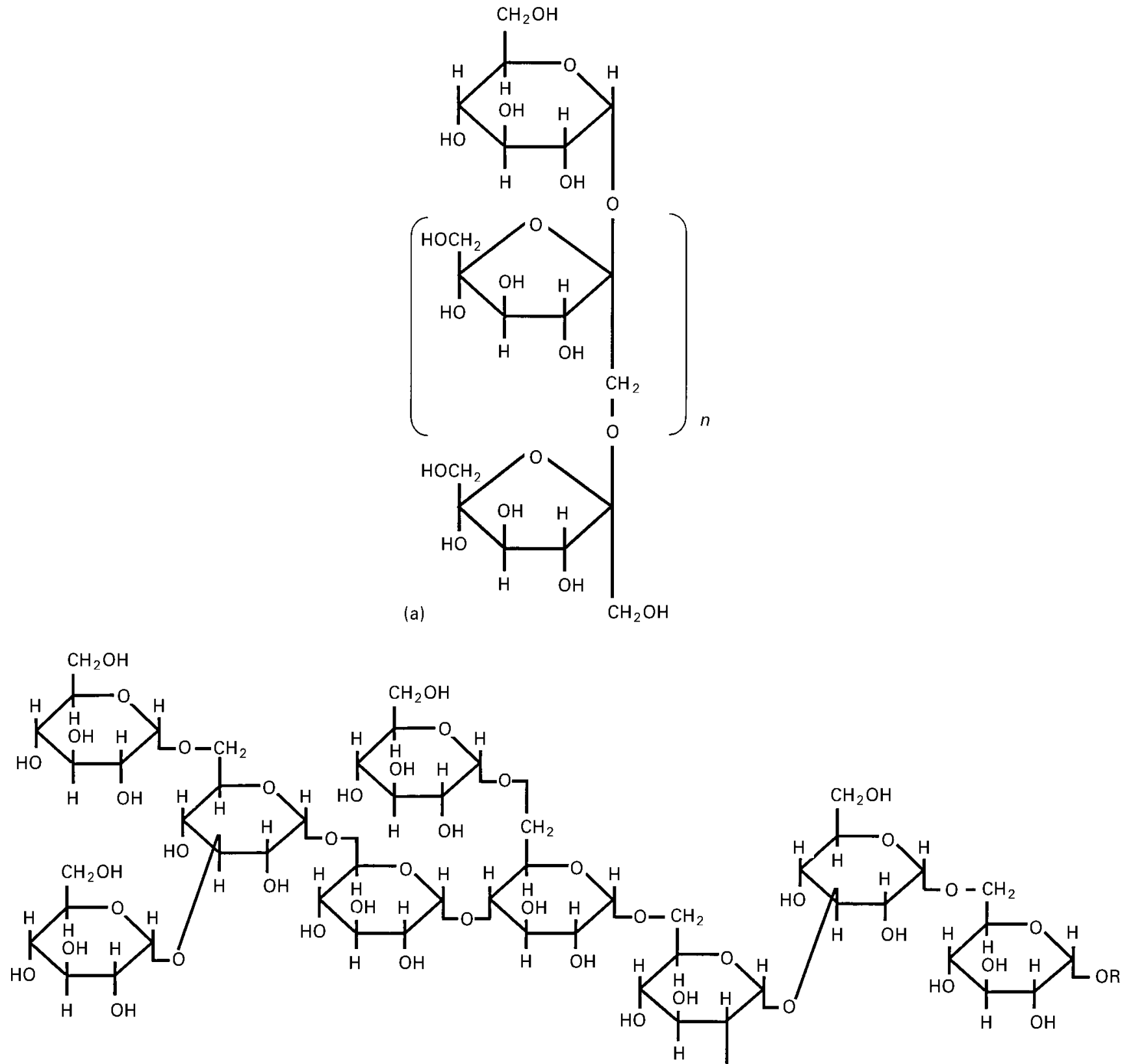

(b)

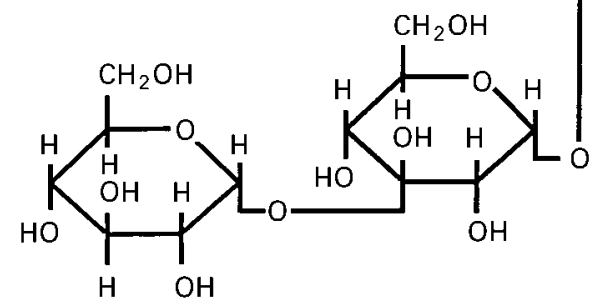

$\mathrm{R}=\mathrm{H}$, sorbitol or more polydextrose units

Fig. 1. Structure of some non-polyol low-digestible carbohydrates. (a) Fructo-oligosaccharide: e.g. inulin, $n=2-60$; oligofructose, $n=2-20$. (b) Polydextrose. (c) Galacto-oligosaccharide.

and di- or polysaccharides. The properties of these materials depend on their chemical structure, molecular weight and levels of mono- and disaccharides. For example, low-molecular-weight ingredients can alter food-freezing temperature. Longer chain oligosaccharides can increase body and mouthfeel and are useful in beverages or as fat replacers. However, it is the physiological properties of these materials that have created the most interest, these being their reduced energy value, potential hypocariogenic and bifidogenic properties and dietary fibre like effects (Playne \& Crittenden, 1996; Roberfroid, 1993). 


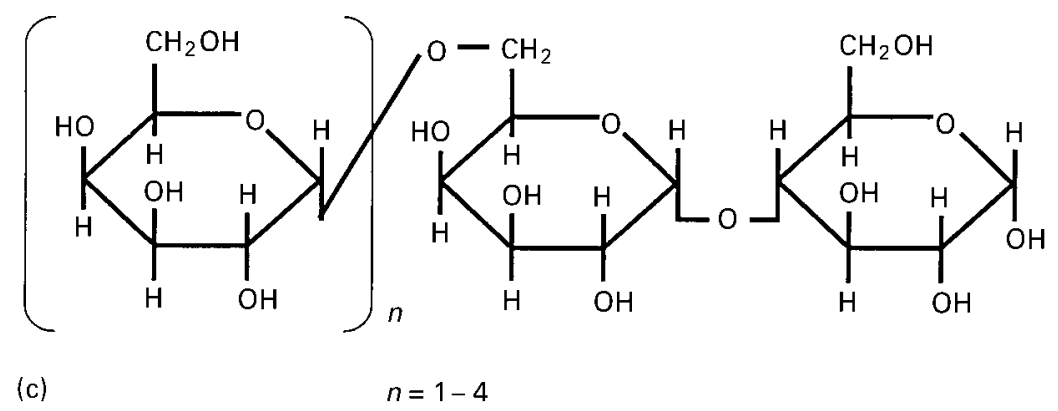

Fig. 1. Continued.

There are currently approximately 12 classes of food grade oligosaccharides in commercial production (Table 4). Most are either synthesised from simple sugars, such as sucrose or lactose, or they can be formed by the controlled hydrolysis of starch or other polysaccharides. Of these, lactose is used as the starting material for the three oligosaccharides: galacto-oligosaccharide, lactulose and lactosucrose (Fig. 1). Galacto-oligosaccharides are found naturally in human milk (McVeagh \& Miller, 1997) and have been associated with the establishment of bifidus flora in breast-fed infants (Rubaltelli et al. 1998). The inclusion of galacto-oligosaccharides as prebiotic food ingredients has attracted considerable commercial interest and they are now manufactured commercially. Lactulose is produced by the conversion of the glucose moiety in lactose into a fructose residue. Lactulose is completely malabsorbed in the upper intestine and it is suggested that it has some prebiotic effects (Kontula et al. 2000). It is used predominantly as a pharmaceutical in the treatment of constipation and hepatic encephalopathy (Bircher et al. 1966; Clausen \& Mortensen, 1997), but there is emerging interest in its bifidogenic effects when included in infant milk formulas (Baskaran et al. 1999). The trisaccharide lactosucrose is an oligosaccharide with potential bifidogenic effects and is derived from lactose in which a lactose molecule has a fructose moiety joined at the glucose residue by a $\beta(2 \rightarrow 1)$ glycosidic bond (Fujita et al. 1992).

Fructo-oligosaccharides represent one of the major classes of bifidogenic oligosaccharides in terms of production volume (Tomomatsu, 1994). They are manufactured by two different processes which result in slightly different

Table 4. Food grade oligosaccharides (Playne \& Crittenden, 1996)

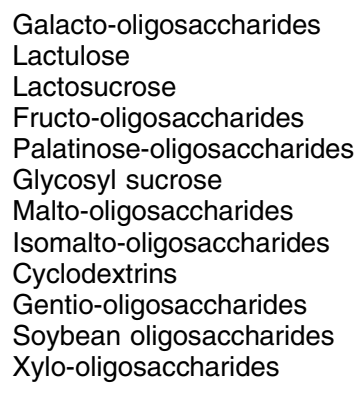

endproducts. In the first method, they are produced from sucrose by transfructosylation and the fructo-oligosaccharide formed contains between two and four $\beta(2 \rightarrow 1)$-linked fructosyl units linked to the terminal $\alpha$-D-glucose residue. The second method used for fructo-oligosaccharide production is the controlled enzyme hydrolysis of inulin. Not all of the $\beta(2 \rightarrow 1)$-linked fructosyl chains end with a terminal glucose and the oligosaccharide mixture produced contains longer fructo-oligomer chains than that produced by the sucrose transfructosylation process (Crittenden \& Playne, 1996). From a chemical point of view there is almost no difference between inulin and fructo-oligosaccharides. They are both oligomers of fructose, the monomers being linked by $\beta(2 \rightarrow 1)$ glycosidic bonds. Whereas inulin has a distribution of molecules with chain lengths of 2-60 units, the chain lengths for oligofructose range from two to ten units with an average DP of 4 (Niness, 1999).

Oligofructose is used to modify the nutritional and organoleptic properties of foods particularly low-calorie foods and those with specific effects on gut function. Such effects are based on the physiological and functional characteristics of these materials. For the purpose of food labelling it is recommended that oligofructose (as with inulin) is given an energy value of $6.28 \mathrm{~kJ} / \mathrm{g}$ (Roberfroid, $1999 a$ ), although human studies suggest an energy value of $9.5 \mathrm{~kJ} / \mathrm{g}$ (Molis et al. 1996). Studies have shown that these materials are selectively fermented in the colon by bifidobacteria, which subsequently grow at the expense of less beneficial bacteria (Tomomatsu, 1994; Gibson \& Roberfroid, 1995).

Oligofructose possesses functional qualities similar to those of sugar or glucose syrup. It is more soluble than sucrose and provides $30-50 \%$ of the sweetness of table sugar. Oligofructose is often used in combination with high intensity sweeteners to replace sucrose, provide a balanced sweetness profile and mask the aftertaste of aspartame or acesulfame K (Wiedmann \& Jager, 1997). Oligofructose is hygroscopic and has humectant properties (De Soete, 2000). Examples of its use in food products include the following.

(1) Light jam products: oligofructose can be used as the sole sweetening agent and gives $34 \%$ calorie reduction compared with the sucrose standard. Organolep- 
tic characteristics of the products are claimed to be very similar, with the test sample having a lower sweetness and a softer texture.

(2) Ice cream: oligofructose can be used with inulin to replace all the sugar and reduce the fat content and give excellent mouthfeel characteristics. Since the freezing point depression is less with oligofructose than with sugar, the texture can be harder.

(3) Confectionery applications: hard candies, gums and marshmallows can be made while achieving significantly reduced energy values.

\section{Resistant starch}

Another class of carbohydrates with low digestibility that has increased in popularity in recent years owing to its physiological and functional characteristics is resistant starch (RS) (Yue \& Waring, 1998). RS may be defined as the sum of starch and products of starch degradation not absorbed in the small intestine and classified as RS that is physically inaccessible to amylase (RS1), naturally resistant or gelatinised starch (RS2) and retrograded starch (RS3) (Wisker, 2000). In cereals, four classes of RS have been identified, these being native starch, retrograde amylose, the amylolipid complex and encapsulated gelatinised starch (Bornet, 1993). RS is fermented by large bowel microflora and may be classified as a dietary fibre (Asp, 1997; Bjorck \& Asp, 1994). RS has an estimated energy value of $11.7 \mathrm{~kJ} / \mathrm{g}$ (Behall \& Howe, 1996) and it is suggested that RS has some prebiotic and hypolipidaemic effects (Brown et al. 1997; Dedeckere et al. 1993). Furthermore, colonic fermentation of RS (in common with non-starch polysaccharides and oligosaccharides) produces short-chain fatty acids, notably butyric acid (Jenkins et al. 1988) which has reportedly significant antineoplastic effects in vitro and in vivo (Vanmunster \& Nagengast, 1993). There is growing evidence that butyric acid has a protective role in the development of colorectal cancers (Scheppach et al., this issue).

RS can be found in both unprocessed foods such as raw potatoes and bananas (Kingman \& Englyst, 1994; Wisker, 2000) and in processed foods such as pasta and bread (Brighenti et al. 1988). Although highly discussed in the 1980s, no significant attempts were made to commercialise RS until the 1990s. Commercial RS food-grade products are obtained by the controlled retrogradation of partially hydrolysed amylose leading to the formation of insoluble crystallates.

The processing technology involved allows distinct physical and functional properties to be achieved. Owing to its white colour, bland taste and microparticulate structure, RS can be easily incorporated in food without altering the texture and appearance. It can be used as a fat mimetic or to increase the dietary fibre content of food (Würsch, 1999).

Incorporation of RS may result in positive textural enhancement of low moisture foods, such as crackers and cookies. In extruded cereals, RS contributes greater crispness and better expansion. In pasta products the use of RS can increase the total fibre content while avoiding the grainy or discoloured appearance that results from the inclusion of commonly used fibres (Ranhotra et al. 1999).

\section{Polydextrose}

Polydextrose (PD) is now used widely across most sectors of the food industry. It is a randomly bound polymer of glucose containing small amounts of sorbitol and citric acid (Moppett, 1991) (Fig. 1). The original polydextrose has been subject to various clean up procedures to produce several qualities of material.

The random bonds in the PD polymer prevent mammalian digestive enzymes from readily hydrolysing the molecule and it has a reported reduced energy value of $4.18 \mathrm{~kJ} / \mathrm{g}$ (Figdor \& Rennhard, 1981). However, the metabolisable energy value of PD is higher compared to values obtained by radiochemical balance procedures (Cooley \& Livesey, 1987). It is an odourless, white to cream amorphous powder with virtually no sweetness. PD takes part in the Maillard reaction and so allows characteristic caramel and toffee colours to develop.

PD is highly soluble in water (approximately $80 \% \mathrm{w} / \mathrm{w}$ at $20^{\circ} \mathrm{C}$ ) and solutions have a higher viscosity than sucrose or sorbitol solutions at equivalent concentrations and temperatures. This characteristic enables PD to provide the desirable mouthfeel and textural qualities when replacing sugars and fats. For example, in spoonable and pourable dressings with reduced levels of oil, it provides some of the functionality of the oil by providing mouthfeel, viscosity and bulk (Kappas et al. 1993).

An important characteristic of PD is that it has water activity closely resembling that of sucrose and can function as a humectant helping to slow down undesirable changes in the moisture content of foods. This prolongs shelf-life. In short crust pastry, the fat content can be reduced by up to $50 \%$ with the addition of polydextrose while maintaining the texture normally associated with traditional full-fat pastry. Its addition can increase crispness, reduce pastry shrinkage and improve the machinability of very thin sheets of dough without affecting the organoleptic quality of the product.

PD can be used to replace both sucrose and fat in chocolate and toffee confectionery (Zumbé et al., this issue). This has led to the development of 'light', reducedcalorie and 'tooth-friendly' products which utilise hydrogenated PD that does not contain residual cariogenic monosaccharides. In chocolate, PD contributes good taste characteristics and balances the taste profile of polyolbased sugar-free chocolate. Since PD has a higher viscosity than simple sugars and polyols at equivalent concentrations, it can contribute to the creamy mouthfeel of products (Mitchell, 1996).

\section{Conclusion}

The market for LDCs is substantial and continues to expand. This has been encouraged by an increased consumer awareness of the health benefits of consuming higher levels of dietary fibre. Although dominated by Japanese companies, European interest is growing rapidly and a wide variety of products displaying novel physiolo- 
gical and functional characteristics has emerged. As the beneficial functional properties of LDCs become more widely understood, both the volume of use and the diversity of applications are expected to increase. Further developments in the carbohydrate materials themselves are in progress and it is likely that more novel ingredients demonstrating new physiological effects will emerge over the next few years. At present, materials possessing dietary fibre effects and prebiotic activity are popular and their use in symbiotic products containing probiotic bifidobacteria and prebiotic oligosaccharides is one of the largest emerging markets.

\section{References}

Asp NG (1997) Resistant starch - an update on its physiological effects. Advances in Experimental Medicine and Biology 427, 201-210

Baskaran V, Narasimhamurthy K, Nagendra R \& Lokesh BR (1999) Safety evaluation of lactulose syrup in rats. Journal of Food Science and Technology-Mysore 36, 355-357.

Behall KM \& Howe JC (1996) Resistant starch as energy. Journal of the American College of Nutrition 15, 248-254.

Bircher J, Müller J, Guggenheim P \& Haemmerli UP (1966) Treatment of chronic portal-systemic encephalopathy with lactulose. Lancet i, 890-892.

Bjorck I \& Asp NG (1994) Controlling the nutritional properties of starch in foods - a challenge to the food-industry. Trends in Food Science \& Technology 5, 213-218.

Bornet F (1993) Technological treatments of cereals - repercussions on the physiological properties of starch. Carbohydrate Polymers 21, 195-203.

Brighenti F, Casiraghi MC \& Baggio C (1998) Resistant starch in the Italian diet. British Journal of Nutrition 80, 333-341.

British Nutrition Foundation (1990) Complex Carbohydrates in Foods. The Report of the British Nutrition Foundation's Task Force on Complex Carbohydrates. London: Chapman and Hall.

Brown I, Warhurst M, Arcot J, Playne M, Illman RJ \& Topping DL (1997) Fecal numbers of bifidobacteria are higher in pigs fed Bifidobacterium longum with a high amylose cornstarch than with a low amylose cornstarch. Journal of Nutrition 127, 1822-1827.

Clausen MR \& Mortensen PB (1997) Lactulose, disaccharides and colonic flora. Clinical consequences. Drugs 53, 930-942.

Comber L (1999) The European 'Healthier' Food and Drinks Market. Leatherhead Food RA, Randalls Rd, Leatherhead, Surrey, KT22 7RY, UK.

Cooley S \& Livesey G (1987) The metabolizable energy value of polydextrose in a mixed diet fed to rats. British Journal of Nutrition 57, 235-243.

Crittenden RG \& Playne MJ (1996) Production, properties and applications of food-grade oligosaccharides. Trends in Food Science and Technology 7, 353-361.

Dedeckere EAM, Kloots WJ \& Vanamelsvoort JMM (1993) Resistant starch decreases serum total cholesterol and triacylglycerol concentrations in rats. Journal of Nutrition 123, 21422151.

De Soete J (2000) Prebiotic ingredients in chewing gum - the use of inulin and oligofructose. Manufacturing Confectioner 80, 67-69.

Dreher M (1999) Food sources and uses of dietary fibre. In Complex Carbohydrates in Foods, pp. 385-394 [SS Cho, editor]. New York: Marcel Dekker.

Figdor SK \& Rennhard HH (1981) Caloric utilisation and disposition of ${ }^{14} \mathrm{C}$-polydextrose in the rat. Journal of Agricultural and Food Chemistry 29, 1181-1189.

Franck A (1997) Gums and stabilisers for the food industry. Proceedings of the 9th conference, Wrexham, July 1977, pp. 409-412 [PA Williams and GO Phillips, editors]. Cambridge: Royal Society of Chemistry.

Fujita K, Kitahata S, Kozu H \& Hotoshi H (1992) Production of lactosucrose and its properties. In Carbohydrates in Industrial Synthesis, pp. 68-76 [MA Clarke, editors]. Proceedings of the Symposium of the Division of Carbohydrate Chemistry of the American Chemical Society. Berlin: Bartens.

Gibson GR \& Roberfroid MB (1995) Dietary modulation of the human colonic microbiota - introducing the concept of prebiotics. Journal of Nutrition 125, 1401-1412.

Hilliam M (1998) The market for functional foods. International Dairy Journal 8, 349-353.

Hilliam M, James A \& Young J (1997) The European Market for Functional Foods - Current Developments and Future Prospects. Leatherhead Food RA, Randalls Rd, Leatherhead, Surrey, KT22 7RY, UK.

Jenkins DJA, Vuksan V, Kendall CWC, Würsch P, Jeffcoat R, Waring S, Mehling CC, Vidgen E, Augustin LSA \& Wong E (1988) Physiological effects of resistant starches on fecal bulk, short chain fatty acids, blood lipids and glycemic index. Journal of the American College of Nutrition 17, 609-616.

Kappas JD, Kupchik FM \& Moppett FK (1993) Litesse. In Science for the Food Industry of the 21st Century, Biotechnology, Supercritical Fluids, Membranes and Other Advanced Technologies for Low Calorie, Healthy Food Alternatives, 1(3) [M Yalpani, editor]. Mount Prospect, IL: AALT Press.

Kingman SM \& Englyst HN (1994) The influence of food preparation methods on the in-vitro digestibility of starch in potatoes. Food Chemistry 49, 181-186.

Kontula P, Suihko ML, Suortti T, Tenkanen M, MattilaSandholm T \& Von-Wright A (2000) The isolation of lactic acid bacteria from human colonic biopsies after enrichment on lactose derivatives and rye arabinoxylo-oligosaccharides. Food Microbiology 17, 13-22.

Kruse HP, Kleessen B \& Blaut M (1999) Effects of inulin on faecal bifidobacteria in human subjects. British Journal of Nutrition 82, 375-382.

McVeagh P \& Miller JB (1997) Human milk oligosaccharides: only the breast. Journal of Paeditrics and Child Health 33, 281-286.

Mitchel HL (1996) The role of the bulking agent polydextrose in fat replacement. In Handbook of Fat Replacers, pp. 235-249 [S Roller and SA Jones, editors]. Boca Raton: CRC Press.

Molis C, Flourie B, Ouarne F, Gailing MF, Lartigue S, Guibert A, Bornet F \& Galmiche JP (1996) Digestion, excretion, and energy value of fructooligosaccharides in healthy humans. American Journal of Clinical Nutrition 64, 324-328.

Moppett FK (1991) Polydextrose. In Alternative Sweeteners, pp. 401-421 [L O'Brien Nabors and RC Gelardi, editors]. New York: Marcel Dekker.

Niness KR (1999) Inulin and oligofructose: what are they? Journal of Nutrition 129, S1402-S1406.

Playne MJ \& Crittenden R (1996) Commercially available oligosaccharides. Bulletin of the IDF 313, 10-22.

Ranhotra G, Gelroth J \& Leinen S (1999) Resistant starch - a new ingredient for use in processed foods. AIB Technical Bulletin 21, 1-8.

Roberfroid MB (1993) Dietary fiber, inulin, and oligofructose - a review comparing their physiological effects. Critical Reviews in Food Science and Nutrition 33, 103-148.

Roberfroid MB (1999a) Caloric value of inulin and oligofructose. Journal of Nutrition 129, S1436-S1437.

Roberfroid MB (1999b) Concepts in functional foods: the case of 
inulin and oligofructose. Journal of Nutrition 129, S1398S1401.

Roberfroid MB, Van Loo JAE \& Gibson GR (1998) The bifidogenic nature of chicory inulin and its hydrolysis products. Journal of Nutrition 128, 11-19.

Rubaltelli FF, Biadaioli R, Pecile P \& Nicoletti P (1998) Intestinal flora in breast and bottle-fed infants. Journal of Perinatal Medicine 26, 186-191.

Silva RF (1996) Use of inulin as a natural texture modifier. Cereal Foods World 41, 1-8.

Tomomatsu H (1994) Health effects of oligosaccharides. Food Technology 48, 61-65.

Van Loo J (1995) Natural occurrence of inulin and oligofructose. 1st Orafti Research Conference, Universite Catholique de Louvain, 17 January, 1995, pp. 119-130.

Van Loo J, Coussement P, Deleenheer L, Hoebregs H \& Smits G (1995) On the presence of inulin and oligofructose as natural ingredients in the Western diet. Critical Reviews in Food Science and Nutrition 35, 525-552.

Van Loo J, Cummings J, Delzenne N, Englyst H, Franck A, Hopkins M, Kok N, Macfarlane G, Newton D, Quigley M, Roberfroid M, van Vliet T \& van den Heuvel E (1999)
Functional food properties of non-digestible oligosaccharides: a consensus report from the ENDO project (DGXII AIRII-CT941095). British Journal of Nutrition 81, 121-132.

Vanmunster IP \& Nagengast FM (1993) The role of carbohydrate fermentation in colon-cancer prevention. Scandanavian Journal of Gastroenterology 28, 80-86.

Weidman M \& Jager M (1997) Synergistic sweeteners. Food Ingredients International Nov-Dec, 51-56.

Wisker E (2000) Physiological effects of resistant starch - Part 1: definition, intake with food, and influence on glucose, insulin and lipid plasma levels. Ernahrungs-umschau 47, 10-15.

Wouters E (1998) The benefits of inulin and oligofructose in ice cream. World of Ingredients September, 44-45.

Würsch P (1999) Production of resistant starch. In Complex Carbohydrates in Foods, pp. 385-394 [SS Cho, editor]. New York: Marcel Dekker.

Yue P \& Waring S (1998) Functionality of resistant starch in food applications. Food Australia 50, 615-621.

Young J (1998) European market developments in prebiotic- and probiotic-containing foodstuffs. British Journal of Nutrition $\mathbf{8 0}$, S231-S233. 